\title{
Limits on the adaptability of coastal marshes to rising sea level
}

\author{
Matthew L. Kirwan, ${ }^{1,2}$ Glenn R. Guntenspergen, ${ }^{1}$ Andrea D’Alpaos, ${ }^{3}$ James T. Morris, ${ }^{4}$ \\ Simon M. Mudd, ${ }^{5}$ and Stijn Temmerman ${ }^{6}$ \\ Received 13 September 2010; revised 18 October 2010; accepted 21 October 2010; published 1 December 2010.
}

[1] Assumptions of a static landscape inspire predictions that about half of the world's coastal wetlands will submerge during this century in response to sea-level acceleration. In contrast, we use simulations from five numerical models to quantify the conditions under which ecogeomorphic feedbacks allow coastal wetlands to adapt to projected changes in sea level. In contrast to previous sea-level assessments, we find that non-linear feedbacks among inundation, plant growth, organic matter accretion, and sediment deposition, allow marshes to survive conservative projections of sealevel rise where suspended sediment concentrations are greater than $\sim 20 \mathrm{mg} / \mathrm{L}$. Under scenarios of more rapid sea-level rise (e.g., those that include ice sheet melting), marshes will likely submerge near the end of the 21 st century. Our results emphasize that in areas of rapid geomorphic change, predicting the response of ecosystems to climate change requires consideration of the ability of biological processes to modify their physical environment. Citation: Kirwan, M. L., G. R. Guntenspergen, A. D’Alpaos, J. T. Morris, S. M. Mudd, and S. Temmerman (2010), Limits on the adaptability of coastal marshes to rising sea level, Geophys. Res. Lett., 37, L23401, doi:10.1029/2010GL045489.

\section{Introduction}

[2] Climate change will cause important alterations to both physical and biological components of landscapes, and understanding system adaptability is crucial to mitigating climate-related risks [Scheffer et al., 2001]. Two-way couplings between biotic and physical processes are just beginning to be recognized as fundamental drivers of landscape evolution, and "the ongoing failure to incorporate these dynamic bio-physical interactions...limits our ability to predict the response of landscapes to human disturbance and climate change [Reinhardt et al., 2010]." Tidal wetlands are among the most valuable ecosystems on earth [Costanza et al., 1997], and represent perhaps the most striking example of a system whose response to climate change may be controlled by ecogeomorphic interactions [e.g., Langley et al., 2009]. Despite decades of concern over their ability to survive rapid rates of sea level rise (SLR) [Reed, 1995],

\footnotetext{
${ }^{1}$ Patuxent Wildlife Research Center, U.S. Geological Survey, Laurel, Maryland, USA.

${ }^{2}$ Department of Environmental Science, University of Virginia, Charlottesville, Virginia, USA.

${ }^{3}$ Dipartimento di Geoscienze, Universita di Padova, Padua, Italy.

${ }^{4}$ Belle W. Baruch Institute for Marine and Coastal Sciences, University of South Carolina, Columbia, South Carolina, USA.

${ }^{5}$ School of GeoSciences, University of Edinburgh, Edinburgh, UK.

${ }^{6}$ Department of Biology, University of Antwerpen, Wilrijk, Belgium.

Copyright 2010 by the American Geophysical Union. 0094-8276/10/2010GL045489
}

system complexity and an inability to discern between reduced sediment delivery rates and accelerated SLR has prevented a simple answer to the important question: at what maximum rate of SLR can a marsh survive?

[3] Assumptions of a static landscape inspire predictions that $20-60 \%$ of the world's coastal wetlands will submerge in response to sea-level acceleration during this century [Titus, 1988; Nicholls et al., 2007; Craft et al., 2009]. Like many forecasts of ecosystem change, these estimates rely on models where topographic surfaces evolve at historic rates [Craft et al., 2009], where inundation occurs across a static landscape [Cooper et al., 2008], or on comparisons between rates of historical accretion and future SLR [McFadden et al., 2007]. However, coastal ecosystems are known to be highly dynamic environments that have significant capacity to adjust to changes in rates of SLR through non-linear feedback mechanisms. In tidal marshes and mangroves, for example, increasing inundation leads to higher rates of sediment deposition, which helps tidal wetlands keep up with SLR [Reed, 1995]. In salt marshes, vegetation growth is typically more rapid at low elevations and in years of anomalously high sea level [Morris et al., 2002], potentially enhancing sediment trapping and organic matter accretion, and limiting erosion [Fagherazzi et al., 2004]. These types of ecogeomorphic feedbacks likely explain the persistence of wetlands within the intertidal zone over thousands of years in the stratigraphic record [Redfield, 1972], and observations of accretion rates that are highest in regions with historically high rates of SLR [Cahoon et al., 2006]. Nevertheless, widespread observations of marsh submergence today [Reed, 1995; Nicholls et al., 2007] indicate that there are limits to the ability of ecogeomorphic feedbacks to preserve a marsh as a stable ecosystem. Here, we attempt to identify the limits of these feedbacks by quantifying the conditions that lead to marsh drowning in an ensemble of five numerical models that incorporate non-linear feedbacks between inundation, plant growth, and substrate accretion.

\section{Model Approach}

[4] In an attempt to model coastal wetland resilience to sea level rise, we use five numerical models designed to explore how feedbacks between inundation and sediment deposition, and interactions between physical and biological processes, govern the long term evolution of coastal marshland [Morris et al., 2002; Temmerman et al., 2003; D'Alpaos et al., 2007; Kirwan and Murray, 2007; Mudd et al., 2009]. In each of these models, the marsh surface accretes at a rate determined by its elevation relative to sea level, a proxy for the duration of tidal inundation. Since tidal range and suspended sediment availability have been identified as potentially important factors governing salt marsh evolution, we adapt each model to consider the concentration of 

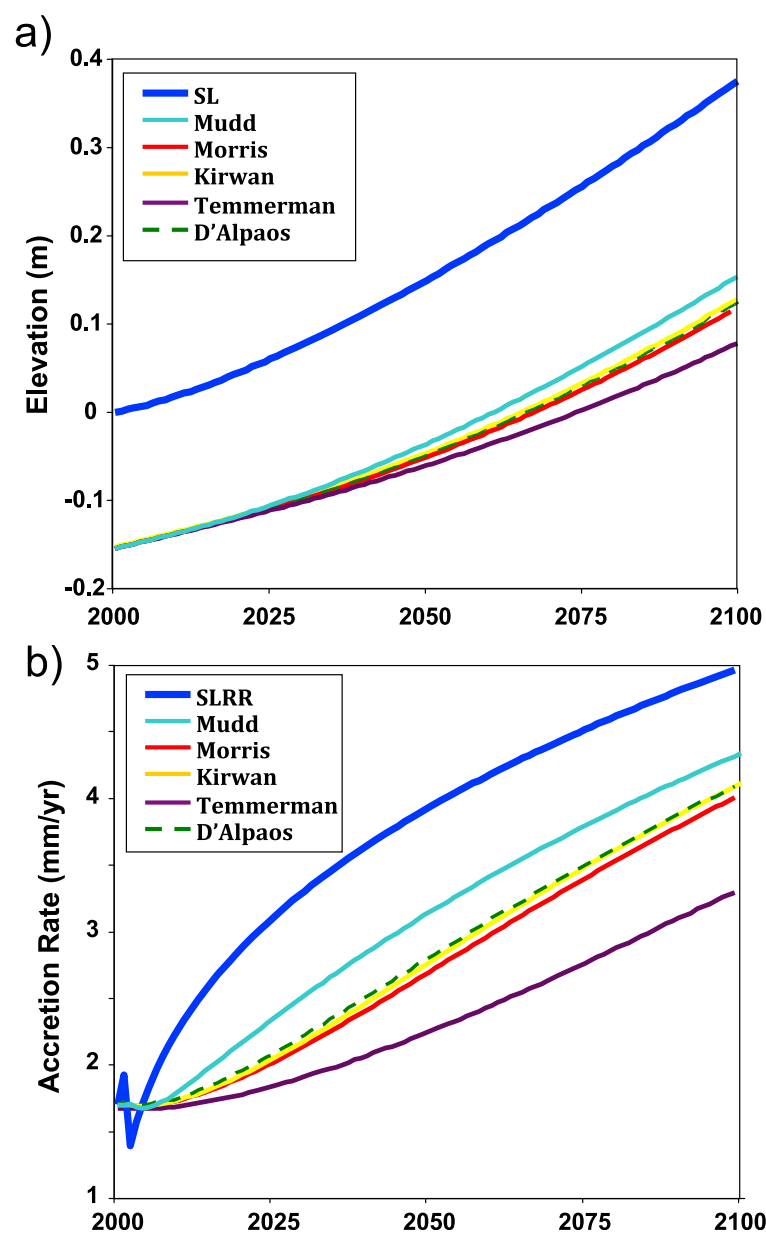

Figure 1. Response of marsh elevation (a) and accretion rate (b) to a conservative sea-level acceleration (IPCC A1B scenario [Bindoff et al., 2007]). Heavy blue line denotes sea level at spring high water (Figure 1a) or the sea-level rise rate (Figure $1 \mathrm{~b}$ ). Elevations reflect the simulated position of the marsh relative to spring high water. Since each model predicts a slightly different initial elevation relative to sea level, we have normalized each model to a common equilibrium elevation at time zero. Since sea-level rise rates tend to exceed accretion rates, marsh elevations adjust to sealevel acceleration by becoming lower relative to sea level (i.e., more inundated) (Figure 1a), which enhances vertical accretion (Figure 1b). (Experimental conditions: spring tidal range $=1 \mathrm{~m}$, suspended sediment concentration $=30 \mathrm{mg} / \mathrm{L}$.)

suspended sediment in the channels adjacent to the marsh platform, and the effects of tidal range on the duration of flooding and its effect on sediment deposition and vegetation growth. We conduct all model experiments using a common vertical datum where marsh elevations are relative to spring high tide, and the elevation range that vegetation can occupy increases proportionately with tidal range [McKee and Patrick, 1988; Kirwan and Guntenspergen, 2010].

[5] Three of the models were designed to represent tidal salt marshes characteristic of North Inlet, SC (USA), one for Venice Lagoon (Italy) and one for the Scheldt Estuary (Netherlands, Belgium). Although substrate accretion rates increase with inundation, each model differs in its approach to modeling vegetation growth, sediment transport, and the reliance on organic vs. mineral accretion. The types of processes considered, and the parameter values chosen, reflect the environment for which each model was designed (please see auxiliary material). ${ }^{1}$ Therefore, our ensemble approach helps preserve the variability in behavior that can be attributed to site differences in natural wetlands and offers some assessment of model uncertainty.

\section{Marsh Response to Accelerating Sea Level Rise}

[6] In a first set of model experiments, we consider the transient behavior of a marsh adjusting to a relatively slow [Bindoff et al., 2007] and a relatively fast [Rahmstorf, 2007] acceleration in the rate of SLR. We begin these experiments with marsh elevations that are in equilibrium with the historical rate of global SLR, which we take to be $1.7 \mathrm{~mm} / \mathrm{yr}$ [Bindoff et al., 2007]. In our 'slow' sea level experiment, sea level accelerates according to mean rates of thermal expansion predicted for the IPCC's A1B scenario [Bindoff et al., 2007]. In our 'fast' sea level experiment, sea level accelerates according to maximum estimates projected from a historical linear relationship between global temperature and the rate of SLR [Rahmstorf, 2007]. While these scenarios of SLR are based on eustatic estimates, the response of an individual marsh is more importantly related to the relative rate of SLR, which could be higher or lower than the eustatic rate depending on whether the land surface is uplifting or subsiding.

[7] In both experiments, marshes adjust to increasing rates of SLR by becoming lower relative to sea level (Figures 1a and $2 \mathrm{a}$ ). For moderate rates of SLR, this leads to enhanced vegetation growth and an accelerating rate of substrate accretion (Figure 1b). However, at faster rates of SLR, the marsh platform deepens beyond depths capable of supporting vegetation (Figure $2 \mathrm{a}$ ). At this point, accretion rates decline (Figure 2b) and the surface quickly loses elevation relative to an accelerating sea level (Figure 2a). Therefore, the rate of SLR which leads to vegetation mortality defines an important threshold for the stability of intertidal landscapes. Our numerical experiments indicate that above this threshold rate, inundation leads to rapid and irreversible conversion of intertidal marshland into unvegetated, subtidal surfaces.

\section{Threshold Rates of Sea Level Rise for Marsh Survival}

[8] In a second set of model experiments, we explore the dependency of this threshold rate of SLR on environmental conditions that vary in estuaries around the world. Specifically, we identify the maximum rate of SLR conducive to wetland stability for different combinations of tidal range and suspended sediment concentration (Figure 3). Our results indicate that the amount of sediment available for accretion strongly influences the maximum rate of SLR that marshes can survive, even for models that consider peat accumulation in detail. Critical rates of SLR are just a few millimeters per year at low suspended sediment concentrations $(\sim 1-10 \mathrm{mg} / \mathrm{L})$, but marshes adapt to SLR rates of several centimeters per year at high suspended sediment concentrations $(30-100 \mathrm{mg} / \mathrm{L})$. We also identify a positive

\footnotetext{
${ }^{1}$ Auxiliary materials are available in the HTML. doi:10.1029/ 2010 GL045489.
} 

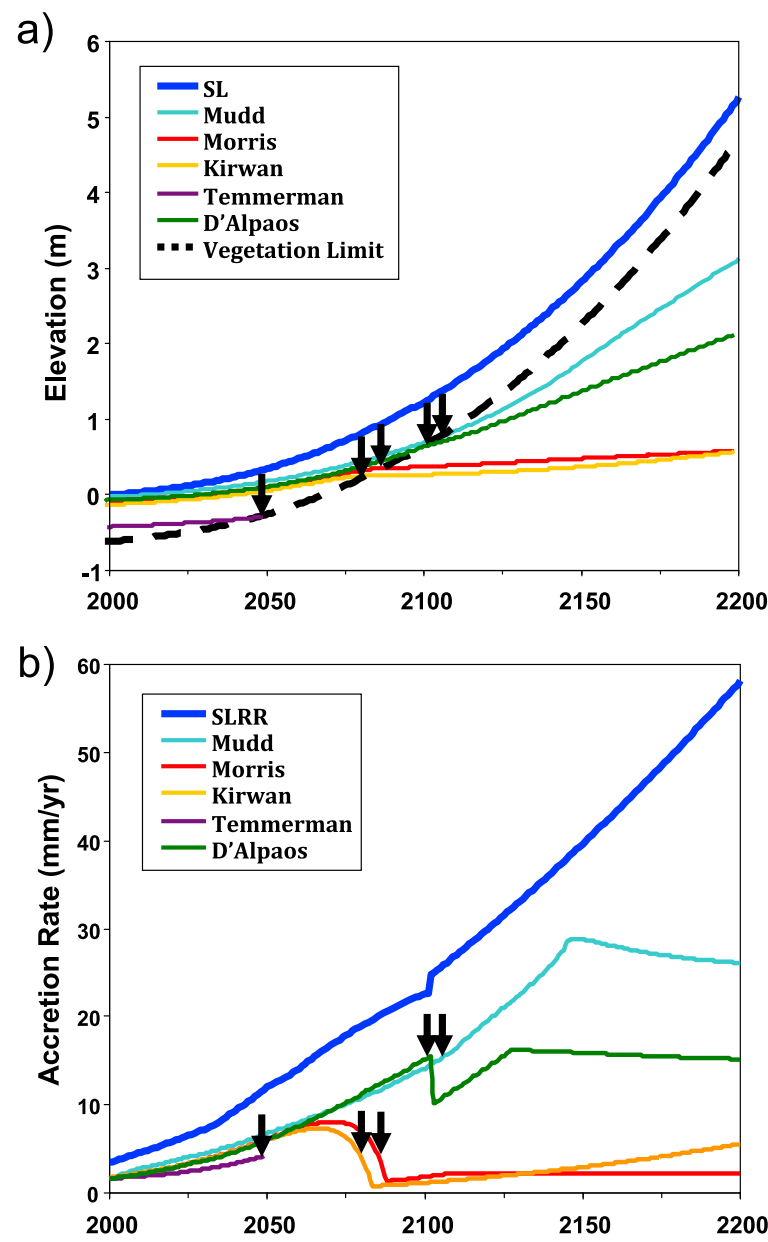

Figure 2. Response of (a) marsh elevation and (b) accretion rate to a rapid sea-level acceleration. Heavy blue line denotes sea level at spring high water (Figure 2a) or the sea-level rise rate (Figure $2 b$ ). Elevations reflect the position of the marsh relative to spring high water. In this model experiment, sea level accelerates according to Rahmstorf's [2007] maximum scenario. We have extrapolated Rahmstorf's scenario from 2100 to $2200 \mathrm{AD}$ using a 3rd degree polynomial fit. Marsh elevations tend to adjust to sea-level acceleration by becoming deeper relative to sea level, although the dashed black line denotes the lowest elevations at which vegetation can grow. Arrows denote the point in each model at which marsh elevations become too low to support vegetation. In most models, vegetation mortality leads to a decrease in accretion. However, mortality leads to a temporary increase in organic accretion in the Mudd model, and does not affect accretion in the Temmerman model. (Experimental conditions: spring tidal range $=1 \mathrm{~m}$, suspended sediment concentration $=30 \mathrm{mg} / \mathrm{L}$.)

relationship, though with more variability, between the threshold rate of SLR and tidal range. For a given suspended sediment concentration, a macrotidal marsh (tidal range $>4 \mathrm{~m}$ ) can adapt to SLR rates up to an order of magnitude greater than a microtidal marsh (tidal range $<2 \mathrm{~m}$ ). Our results also point to an interactive effect, where macrotidal marshes are more sensitive to sediment supply than microtidal marshes. This interdependence makes marshes with high tidal ranges and suspended sediment concentrations extremely resilient to SLR, while making marshes with low tidal ranges and suspended sediment concentrations highly vulnerable.

\section{Discussion}

[9] Our predictions of threshold SLR rates over a large range of sediment concentrations and tidal ranges agree qualitatively with observations from estuaries worldwide that were not used to design or parameterize the models (Figure 3). For example, our modeling framework discerns between two regions of the Mississippi/Atchafalaya River Delta (USA) that have responded to SLR in very different manners despite similar tidal ranges $(<1 \mathrm{~m})$ and relative SLR rates $(\sim 10 \mathrm{~mm} / \mathrm{yr})$. Specifically, our models predict that marshes would survive this rate of relative SLR at sediment concentrations measured in the Old Oyster Bayou region (70 mg/L) [Wang, 1997; Perez et al., 2000], but submerge at concentrations measured in the Bayou Chitique region $(20 \mathrm{mg} / \mathrm{L})$ [Wang, 1997]. These predictions are consistent with observations of stability and rapid accretion in the extensive marshes surrounding Old Oyster Bayou, and observations of rapid submergence and erosion in Bayou Chitique [Cahoon et al., 1995]. At high tidal ranges (TR) and suspended sediment concentrations $(S S C)$, our results suggest that marshes can persist under extremely high rates of relative SLR (i.e., $>100 \mathrm{~mm} / \mathrm{yr}$ ). Marshes in the Yangtze River Delta (China) $(S S C=1000 \mathrm{mg} / \mathrm{L}, T R \sim 5 \mathrm{~m})$ might be a natural analog. Here, marshes persist and even expand

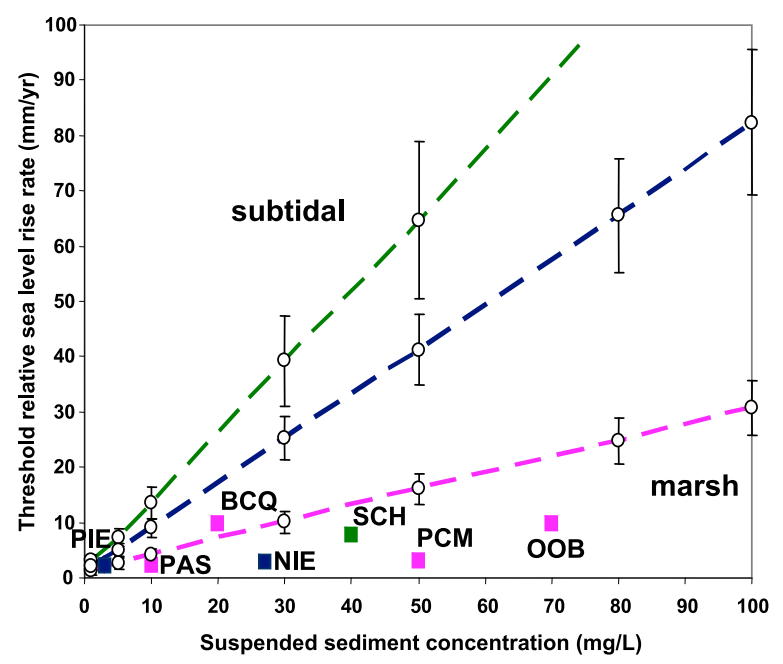

Figure 3. Predicted threshold rates of sea-level rise, above which marshes are replaced by subtidal environments as the stable ecosystem. Each line represents the mean threshold rate $( \pm 1 \mathrm{SE})$ predicted by 5 models as a function of suspended sediment concentration and spring tidal range. Pink line denotes thresholds for marshes modeled under a $1 \mathrm{~m}$ tidal range, blue line denotes $3 \mathrm{~m}$ tidal range, and green line denotes $5 \mathrm{~m}$ tidal range. For reference, we have included examples (denoted with square markers) of marshes worldwide in estuaries with different rates of historical sea-level rise, sediment concentration, and tidal range. (Abbreviations: PIE = Plum Island Estuary, Massachusetts; PAS = Pamlico Sound, North Carolina; BCQ = Bayou Chitique, Louisiana; $\mathrm{NIE}=$ North Inlet Estuary, South Carolina; $\mathrm{SCH}=$ Scheldte Estuary, Netherlands; PCM = Phillips Creek Marsh, Virginia; $\mathrm{OOB}=$ Old Oyster Bayou, Louisiana). 
seaward despite high, subsidence-generated rates of relative SLR by accreting at rates $>50 \mathrm{~mm} / \mathrm{yr}$ [Yang, 1999]. Finally, our models suggest that salt marshes are a stable ecosystem at more intermediate rates of SLR and sediment concentrations. For suspended sediment concentrations greater than $20 \mathrm{mg} / \mathrm{L}$ and tidal ranges greater than $1 \mathrm{~m}$, conditions typical of many estuaries in the southeastern United States and western Europe [French, 2006], our models predict a critical SLR rate of about $10 \mathrm{~mm} / \mathrm{yr}$. This model observation is consistent with the broad, expansive marshes common in the southeastern United States and the rapidly accreting marshes in western Europe, where historical SLR rates are generally about $3 \mathrm{~mm} / \mathrm{yr}$. Therefore, the ability of our modeling framework to predict whether a marsh or subtidal landscape should be the stable ecosystem in an estuary suggests that our ensemble model predictions have quantitative relevance, and are broadly applicable to a wide variety of coastal marshes.

[10] These results suggest that expansive marshes in regions with low tidal ranges or sediment concentrations will likely submerge in the near future, even for conservative projections of SLR. For example, our models predict a threshold SLR rate of about $5 \mathrm{~mm} / \mathrm{yr}$ for marshes in the Plum Island Estuary, the largest estuary in New England (Massachusetts, USA: $S S C=3 \mathrm{mg} / \mathrm{L}, T R=3 \mathrm{~m}$ (C. Hopkinson, Dissolved nutrient and particulate concentrations of freshwater inputs to the Plum Island estuarine system, taken approximately monthly, Plum Island Ecosystem LTER Database, 2007, available at http://ecosystems.mbl.edu/PIE/data/WAT/WATVA-Inputs.html)), and for marshes in the Albemarle-Pamlico Sound, the second largest estuary in the United States (North Carolina, USA: $S S C=10 \mathrm{mg} / \mathrm{L}, T R=0.5 \mathrm{~m}$ [Lunetta et al., 2009]). Although our results confirm a stable marsh ecosystem under historical rates of relative SLR (locally 2-3 mm/yr), projected SLR rates for $2100(\sim 5 \mathrm{~mm} / \mathrm{yr}$, mean IPCC scenario [Bindoff et al., 2007]) exceed this threshold, suggesting that unvegetated, subtidal environments will replace marshes. Our experiments involving the transient behavior of a marsh adjusting to sea level acceleration indicate that drowning occurs $\sim 30-40$ years after threshold rates are exceeded.

[11] Under more rapid projections of SLR (e.g., those that include enhanced contributions from ice-sheet melting), only marshes in high tidal range environments with abundant sediment are likely to remain stable. Our models predict that at SLR rates beyond $20 \mathrm{~mm} / \mathrm{yr}$ [Rahmstorf, 2007], only marshes in regions with tidal ranges greater than $3 \mathrm{~m}$ and sediment concentrations above $30 \mathrm{mg} / \mathrm{L}$ will survive. Under more typical conditions (e.g., $S S C=30 \mathrm{mg} / \mathrm{L}, T R=1 \mathrm{~m}$ as simulated in Figure 1), all five models predict that inundation depths on the marsh platform will exceed those capable of supporting vegetation near the end of the 21 st century, marking the transition to a subtidal landscape.

[12] Assumptions of a static landscape, or a landscape that evolves according to linear historical trends, dominate projections of coastal ecosystem change. Here, by explicitly modeling the dynamic feedbacks between inundation, vegetation, and sedimentation, we discover and quantify two important components of wetland response to SLR that cannot be captured by static models. First, marsh survival strongly depends on sediment availability. This raises the possibility that extensive marshes that are degrading today (e.g., Chesapeake Bay, coastal Louisiana [Reed, 1995]) were stable ecosystems during periods of high sediment delivery, but would be unstable today even at relatively low SLR rates. Since dam construction, regional reforestation, and agricultural sediment-control practices continue to lower sediment yields to the coast [Syvitski et al., 2009], we suggest extant coastal wetlands, many of which formed during periods of high sediment deposition in the past, became increasingly prone to ecological collapse as sediment supplies declined.

[13] A second implication is that marsh submergence is not the inevitable outcome of sea-level acceleration that static models predict, but instead depends strongly on the magnitude of 21 st century climate change and the influence of terrestrial ice sheets on global sea level. If global temperature warming follows conservative IPCC projections and ice sheets contribute little water to the oceans, our model experiments indicate that many marshes will accrete vertically and maintain their position within the intertidal zone. However, if temperature warming follows more rapid scenarios and/or ice sheets contribute significant water such that sea level rises by more than a meter in the next 100 years, our models indicate that most marshes will permanently submerge despite their tendency to accrete more quickly.

[14] Acknowledgments. This work was supported by the U.S. Geological Survey Global Change Research Program and the National Science Foundation (EAR 1617209). We thank Jim Grace, Pat Megonigal, and two anonymous reviewers for their suggestions.

\section{References}

Bindoff, N. L., et al. (2007), Observations: Oceanic climate change and sea level, in Climate Change 2007: The Physical Science Basis. Contribution of Working Group I to the Fourth Assessment Report of the Intergovernmental Panel on Climate Change, edited by S. Solomon et al., pp. 385432, Cambridge Univ. Press, Cambridge, U. K

Cahoon, D. R., D. J. Reed, and J. W. Day Jr. (1995), Estimating shallow subsidence in microtidal salt marshes of the southeastern United States: Kaye and Barghoorn revisited, Mar. Geol., 128, 1-9, doi:10.1016/00253227(95)00087-F.

Cahoon, D. R., et al. (2006), Coastal wetland vulnerability to relative sea-level rise: wetland elevation trends and process controls, in Wetlands and Natural Resource Management: Ecological Studies, vol. 190, edited by J. T. A. Verhoeven et al., pp. 271-292, doi:10.1007/978-3540-33187-2 12, Springer, Berlin.

Cooper, M. J. P., M. D. Beevers, and M. Oppenheimer (2008), The potential impacts of sea level rise on the coastal region of New Jersey, USA, Clim. Change, 90, 475-492, doi:10.1007/s10584-008-9422-0.

Costanza, R. R., et al. (1997), The value of the world's ecosystem services and natural Capital, Nature, 387, 253-260, doi:10.1038/387253a0.

Craft, C., et al. (2009), Forecasting the effects of accelerated sea-level rise on tidal marsh ecosystem services, Front. Ecol. Environ, 7, 73-78, doi:10.1890/070219.

D’Alpaos, A., S. Lanzoni, M. Marani, and A. Rinaldo (2007), Landscape evolution in tidal embayments: modeling the interplay of erosion, sedimentation, and vegetation dynamics, J. Geophys. Res., 112, F01008, doi:10.1029/2006JF000537.

Fagherazzi, S., M. Marani, and L. K. Blum (Eds.) (2004), The Ecogeomorphology of Tidal Marshes, Coastal Estuarine Stud., vol. 59, AGU, Washington, D. C

French, J. (2006), Tidal marsh sedimentation and resilience to environmental change: Exploratory modeling of tidal, sea-level, and sediment supply forcing in predominantly allochthonous systems, Mar. Geol., 235, 119136, doi:10.1016/j.margeo.2006.10.009.

Kirwan, M. L., and G. R. Guntenspergen (2010), The influence of tidal range on the stability of coastal marshland, J. Geophys. Res., 115, F02009, doi:10.1029/2009JF001400.

Kirwan, M. L., and A. B. Murray (2007), A coupled geomorphic and ecological model of tidal marsh evolution, Proc. Natl. Acad. Sci. U. S. A., 104, 6118-6122, doi:10.1073/pnas.0700958104

Langley, J. A., K. L. McKee, D. R. Cahoon, J. A. Cherry, and J. P. Megonigal (2009), Elevated $\mathrm{CO}_{2}$ stimulates marsh elevation gain, counterbalancing sea-level rise, Proc. Natl. Acad. Sci. U. S. A., 106, 6182-6186. 
Lunetta, R. S., et al. (2009), Measurement of water colour using AVIRIS imagery to assess the potential for an operational monitoring capability in the Pamlico Sound Estuary, USA, Int. J. Remote Sens., 30, 32913314, doi:10.1080/01431160802552801.

McFadden, L., T. Spencer, and R. J. Nicholls (2007), Broad-scale modeling of coastal wetlands: What is required?, Hydrobiologia, 577, 5-15, doi:10.1007/s10750-006-0413-8.

McKee, K. L., and W. H. Patrick Jr. (1988), The relationship of smooth cordgrass (Spartina alterniflora) to tidal datums: A review, Estuaries, 11, 143-151, doi:10.2307/1351966.

Morris, J. T., P. V. Sundareshwar, C. T. Nietch, B. Kjerfve, and D. R. Cahoon (2002), Responses of coastal wetlands to rising sea level, Ecology, 83 , 2869-2877, doi:10.1890/0012-9658(2002)083[2869:ROCWTR]2.0. $\mathrm{CO} ; 2$.

Mudd, S. M., S. M. Howell, and J. T. Morris (2009), Impact of dynamic feedbacks between sedimentation, sea-level rise, and biomass production on near-surface marsh stratigraphy and carbon accumulation, Estuarine Coastal Shelf Sci., 82, 377-389, doi:10.1016/j.ecss.2009.01.028.

Nicholls, R. J., et al. (2007), Coastal systems and low-lying areas, in Climate Change 2007: Impacts, Adaptation and Vulnerability. Contribution of Working Group II to the Fourth Assessment Report of the Intergovernmental Panel on Climate Change, edited by M. L. Parry et al., pp. 315-356, Cambridge Univ. Press, Cambridge, U. K.

Perez, B. C., J. W. Day, L. J. Rouse, R. F. Shaw, and M. Wang (2000), Influence of Atchafalaya River discharge and winter frontal passage on suspended sediment concentration and flux in Fourleague Bay, Louisiana, Estuarine Coastal Shelf Sci., 50, 271-290, doi:10.1006/ecss.1999.0564.

Rahmstorf, S. (2007), A semi-empirical approach to projecting future sealevel rise, Science, 315, 368-370, doi:10.1126/science.1135456.

Redfield, A. C. (1972), Development of a New England salt marsh, Ecol. Monogr., 42, 201-237, doi:10.2307/1942263.

Reed, D. J. (1995), The response of coastal marshes to sea-level rise: Survival or submergence?, Earth Surf. Processes Landforms, 20, 39-48, doi:10.1002/esp.3290200105.
Reinhardt, L., D. Jerolmack, B. J. Cardinale, V. Vanacker, and J. Wrigh (2010), Dynamic interactions of life and its landscape: Feedbacks at the interface of geomorphology and ecology, Earth Surf. Processes Landforms, 35, 78-101, doi:10.1002/esp.1912.

Scheffer, M., S. Carpenter, J. A. Foley, C. Folke, and B. Walker (2001), Catastrophic shifts in ecosystems, Nature, 413, 591-596, doi:10.1038/ 35098000.

Syvitski, J. P. M., et al. (2009), Sinking deltas due to human activities, Nat. Geosci., 2, 681-686, doi:10.1038/ngeo629.

Temmerman, S., G. Govers, P. Meire, and S. Wartel (2003), Modelling long-term tidal marsh growth under changing tidal conditions and suspended sediment concentrations, Scheldt estuary, Belgium, Mar. Geol., 193, 151-169, doi:10.1016/S0025-3227(02)00642-4.

Titus, J. G. (1988), Greenhouse effect, sea level rise, and coastal wetlands, EPA Rep. 230-05-86-013, Environ. Prot. Agency, Washington, D. C.

Wang, F. C. (1997), Dynamics of intertidal marshes near shallow estuaries in Louisiana, Wetlands Ecol. Manage., 5, 131-143, doi:10.1023/ A:1008255609987.

Yang, S. L. (1999), Sedimentation on a growing intertidal island in the Yangtze River mouth, Estuarine Coastal Shelf Sci., 49, 401-410, doi:10.1006/ecss.1999.0501.

A. D’Alpaos, Dipartimento di Geoscienze, Universita di Padova, Via Giotto 1, I-3513 Padova, Italy.

G. R. Guntenspergen and M. L. Kirwan, Patuxent Wildlife Research Center, U.S. Geological Survey, 12100 Beech Forest Rd., Laurel, MD 20708, USA. (mkirwan@usgs.gov)

J. T. Morris, Belle W. Baruch Institute for Marine and Coastal Sciences, University of South Carolina, Columbia, SC 29208, USA.

S. M. Mudd, School of GeoSciences, University of Edinburgh, Drummond Street, Edinburgh EH8 9XP, UK.

S. Temmerman, Department of Biology, University of Antwerpen, Universiteitsplein 1, B-2610 Wilrijk, Belgium. 